\title{
High-Temperature Crystallization of Thermostable T1 Lipase
}

\begin{abstract}
The gene encoding thermostable T1 lipase secreted by Geobacillus sp. strain $\mathrm{T} 1$ has been overexpressed in a prokaryotic system. Preliminary crystallization was conducted with crystal screen and crystal screen II through a sitting drop vapor diffusion method with $0.5 \mathrm{mg} / \mathrm{mL}$ purified T1 lipase at $16{ }^{\circ} \mathrm{C}$. Crystallization at $16{ }^{\circ} \mathrm{C}$ using formulation 21 of crystal screen II at $2.5 \mathrm{mg} / \mathrm{mL}$ yielded bigger and more defined crystals. Good crystals could easily be obtained as the temperature was increased further while retaining other conditions. In fact, crystallization of $\mathrm{T} 1$ lipase is still possible at $60{ }^{\circ} \mathrm{C}$. The ability to form crystals at $60{ }^{\circ} \mathrm{C}$ is a new discovery in lipase crystallization.
\end{abstract}

Keyword: thermostable T1 lipase, Geobacillus sp. strain T1, crystallization 